\title{
Direct catalytic oxidation and removal of NO in flue gas by the micro bubbles gas-liquid dispersion system
}

\author{
Hongrui Sun ${ }^{1} \cdot$ Guanghui Yang $^{1} \cdot$ Tallal Bin Aftab $^{1} \cdot$ Fei Xue $^{1} \cdot$ Zhengguo Xiao $^{1} \cdot$ Qihao Guo $^{1}$ - Dengxin Li ${ }^{1}$
}

Received: 10 December 2018 / Accepted: 3 December 2019 / Published online: 12 December 2019

(c) The Author(s) 2019

\begin{abstract}
The method of micro bubbles is widely applied in the fields of water and soil treatment. A novel treatment method of NO in flue gas through a gas-liquid two-phase system formed by micro bubbles is proposed in this study. The system depends on the generation of hydroxyl radicals. The NO removal performance of the micro gas-liquid dispersion system induced by catalysts and $\mathrm{O}_{3}$ was explored and the reaction pathways were elucidated. Micro bubbles, $\mathrm{Fe}^{2+}$, and $\mathrm{Mn}^{2+}$ in solution improved NO removal performance significantly. Salinity and surfactants affected the removal performance of NO by altering micro bubbles. In the presence of $\mathrm{Fe}^{2+}$, the $\mathrm{NO}$ removal rate reached $65.2 \%$ at $\mathrm{pH} 5,75.8 \%$ under $0.5 \mathrm{~g} / \mathrm{L} \mathrm{NaCl}$ and $82.1 \%$ under $6 \mathrm{mg} / \mathrm{L}$ sodium dodecyl sulfate. In the presence of $\mathrm{Mn}^{2+}$, the $\mathrm{NO}$ removal rate reached $69.2 \%$ at $\mathrm{pH} 5,83.2 \%$ under $0.5 \mathrm{~g} / \mathrm{L}$ $\mathrm{NaCl}$ and $92.3 \%$ under $6 \mathrm{mg} / \mathrm{L}$ sodium dodecyl sulfate. However, in the presence of both $\mathrm{Mn}^{2+}$ and $\mathrm{Fe}^{2+}$, $\mathrm{NO}$ conversion rate was $93.2 \%$. The $\mathrm{NO}$ removal rate in the presence of $\mathrm{O}_{3}$ was further improved under the same conditions. The study provides the basis for the application and development of micro bubbles in flue gas treatments for NO removal. The results can help to solve the problems of high operating cost, large oxidant consumption, secondary pollution, and high energy consumption in traditional NO removal methods.
\end{abstract}

\section{Graphic abstract}

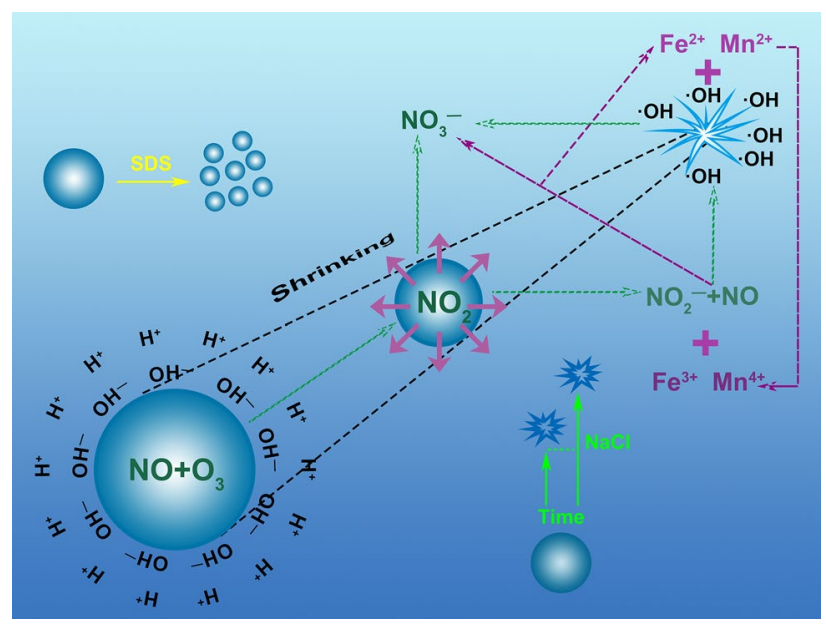

Keywords NO $\cdot$ Micro bubble $\cdot$ Oxidation $\cdot$ Removal $\cdot$ Denitration

Dengxin Li

lidengxin@dhu.edu.cn

Extended author information available on the last page of the article

\section{Introduction}

Micro bubbles (MBs) refer to a kind of bubble mixture whose bubble diameter is between several hundred nanometers and tens of micrometers [1-3]. MBs' residence time 
in water is tens of seconds to several days $[4,5]$. Negatively charged ions (such as $\mathrm{OH}^{-}$) in water are prone to be adsorbed on the surface of MBs, so MBs carry some negative charges $[6,7]$. As the bubble diameter reaches micrometers or even nanometers, the surface tension of the gas-liquid interface compresses the bubbles, thus increasing the specific surface area of bubbles and the oxygen transfer efficiency between gas and liquid [8]. The diameter of MBs is small and the bubble pressure is high. When MBs rupture, they release high energy and hydroxyl radicals [9]. Surfactants, salinity, and $\mathrm{pH}$ affect the properties of MBs [10]. Surfactants make them more stable [11]. Under the conditions of low salinity and low $\mathrm{pH}$, the stability of the MBs is enhanced. Till now, MBs have been extensively explored in environmental applications, especially in surface water restoration [12, 13], agricultural production [14], and ozone oxidation [15]. The NO removal by the micro bubbles gas-liquid dispersion system (MBGLS) has not been reported yet.

$\mathrm{NO}_{\mathrm{x}}$ is one of the major air pollutants and the $\mathrm{NO}$ concentration in flue gas is sometimes as high as 90\% [16]. Due to insoluble $\mathrm{NO}$ [17], it is necessary to oxidize NO into soluble $\mathrm{NO}_{2}$ in wet denitration processes. $\mathrm{NO}$ oxidation methods mainly include photocatalysis [18], plasma oxidation [19], strong-oxidant oxidization [20], and selective catalytic oxidation (SCO) [21, 22]. SCO utilizing catalysts and $\mathrm{O}_{2}$ in flue gas can be combined with traditional wet absorption processes to achieve efficient and integrated desulfurization and denitration and has become the most promising NO oxidation method in industrial applications [23]. However, in order to realize high denitration rate, the NO oxidation methods should be improved in the following three aspects: First, it is necessary to improve the resistances of catalysts to steam, sulfur, and other pollutants so as to ensure the stability of NO oxidation rate. Second, the catalyst cost should be lowered. Third, it is necessary to increase the recovery rate of catalysts. Advanced oxidization processes can be divided into two categories: gas phase oxidation processes and the liquid phase oxidation processes. NO oxidation reactions happen in the gas phase with common oxidants, such as $\mathrm{O}_{2}$, $\mathrm{O}_{3}, \mathrm{Cl}_{2}$, and $\mathrm{CIO}_{2}{ }^{-}$, or in the liquid phase with oxidants [24] such as $\mathrm{Na}_{2} \mathrm{~S}_{2} \mathrm{O}_{8}$ [25], $\mathrm{KMnO}_{4}$ [26], $\mathrm{NaClO}_{2}$ [27], and $\mathrm{H}_{2} \mathrm{O}_{2}$ [28]. The absorption probability of $\mathrm{NO}_{\mathrm{x}}$ can be increased by the addition of various agents $[29,30] . \mathrm{NO}_{\mathrm{x}}$ removal by the oxidation-absorption method has been extensively explored. However, several problems in the NO oxidation-absorption methods remain to be resolved, such as high operation cost, non-recyclable absorption liquid, large oxidant consumption, and the comprehensive use of absorption liquid. Hence, it is imperative to develop a denitration method with high denitration efficiency, low energy consumption, non-secondary pollution, less reagent consumption, high utilization rate of oxidant and low investment.
In order to achieve the high denitration rate, $\mathrm{NO}$ oxidation-absorption removal processes should be improved in the following aspects. First, contact time between NO and oxidant should be long. Second, the oxidation ability of oxidants should be strong. Third, the oxidation reactions or catalysts should not be affected by various pollutants. Fourth, the denitration process should prevent regenerated nitric oxide from escaping for the application in different flue gas environments. The properties of MBs meet the above four conditions. In the study, a new MBGLS generation process utilizing $\mathrm{MB}$ generator is proposed to treat $\mathrm{NO}$ through inhaling water and the mixed gases of $\mathrm{NO}$ and $\mathrm{O}_{3} /$ air. In the process, MBGLS is sprayed into the oxidation-absorption tower, in which NO is oxidized and absorbed. The effects of reaction parameters such as the amount of intake $\left(\mathrm{O}_{3}, \mathrm{NO}\right)$, transition metal ion catalyst $\left(\mathrm{Mn}^{2+}\right.$ and $\left.\mathrm{Fe}^{2+}\right)$, concentration of salt medium $(\mathrm{NaCl})$, and surfactant (sodium dodecyl sulfate, SDS) on the rate of NO oxidation-absorption were explored. This study provides a laboratory theoretical basis for the industrialization of flue gas treatment by micro-nano bubble technology and is expected to achieve flue gas reduction and resource utilization.

\section{Materials and methods}

\section{Experimental materials}

The main experimental devices include micro bubble generator (XZCP-K-0.75), ozone generator (CFT-5G), glass rotor flow meter, UV-Vis spectrophotometer (N4, Shanghai INESA Scientific Instrument Co.), steady-state/transient fluorescence spectrometer (QM/TM*, the United States), and portable $\mathrm{pH}$ meter (MODEL 6010). Sodium hydroxide $(\mathrm{NaOH})$, hydrochloric acid $(\mathrm{HCl})$, sodium chloride $(\mathrm{NaCl})$, SDS, ferrous sulfate $\left(\mathrm{FeSO}_{4} \cdot 7 \mathrm{H}_{2} \mathrm{O}\right)$, manganese sulfate $\left(\mathrm{MnSO}_{4} \cdot 4 \mathrm{H}_{2} \mathrm{O}\right), \mathrm{NO}$ mixture $\left(\mathrm{N}_{2}\right)$, and high-purity $\mathrm{O}_{2}$ were used in the experiments. All chemicals were purchased from Sinopharm Chemical Reagent Co. and used without further purification.

\section{Experimental devices}

Figure 1 is a schematic diagram of an apparatus for NO oxidation and absorption by MBGLS. The entire device consists of a gas distribution system, a water inlet system, a micro bubble generator, and an oxidation-absorption tower. Through controlling the intake of different gases by the gas flow meter (Fig. 1d), $\mathrm{NO}$ and $\mathrm{O}_{3} /$ air are mixed in a gas mixer (Fig. 1f) and then passed into a micro bubble generator (Fig. 1g) together with water (Fig. 1i) to form MBGLS in the oxidation absorber (Fig. 1j). The tail gas is further 


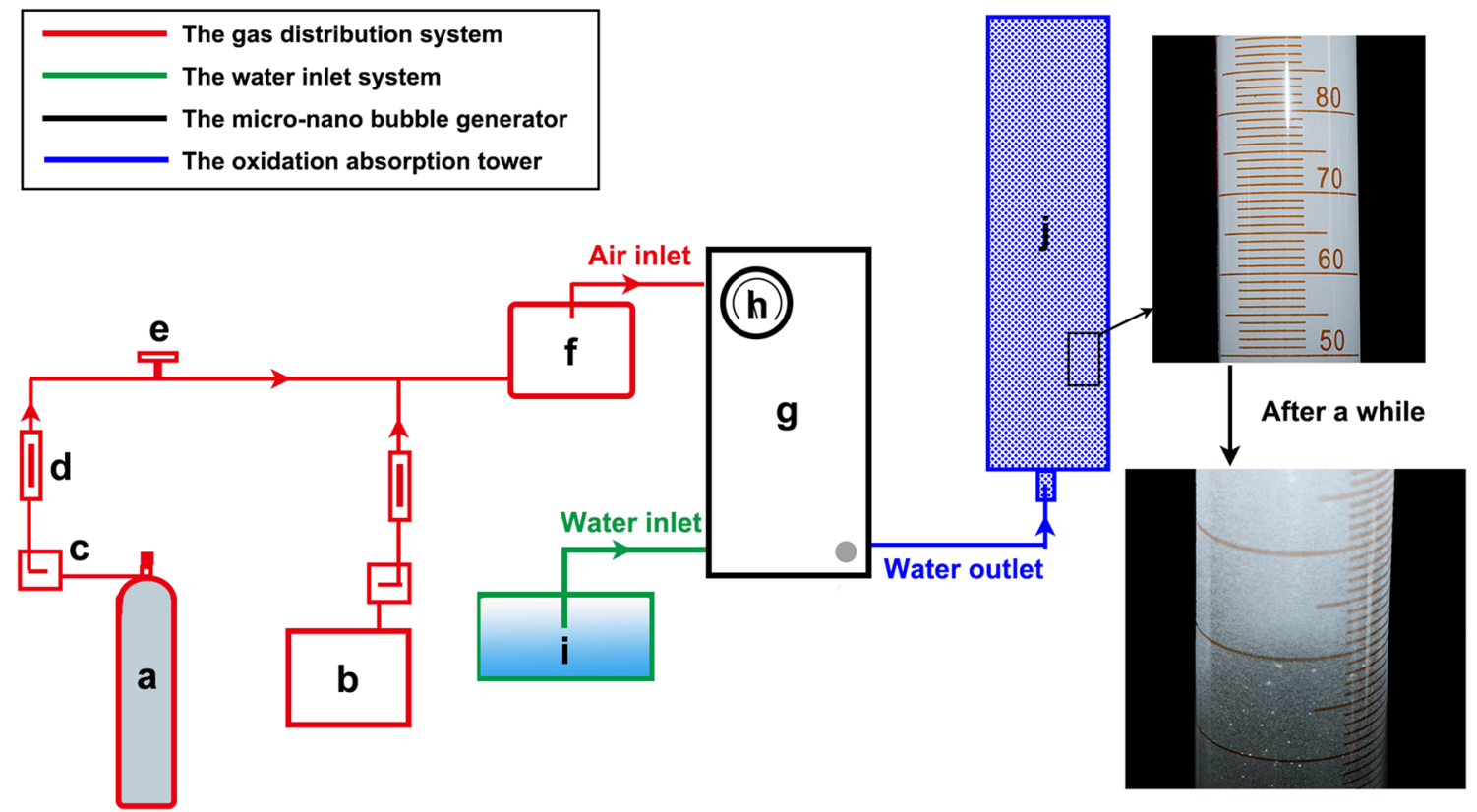

Fig. 1 Oxidation absorption device (a NO cylinder; b ozone generator; c pressure reducing valve and pressure regulating valve; $d$ gas flow meter; e air inlet; f gas mixer; g MB generator; $h$ water pressure gauge; i absorbent; $j$ oxidation-absorption tower)

cleaned by the exhaust gas absorption unit before entering the fume hood.

In the oxidation-absorption process, $\mathrm{air} / \mathrm{O}_{3}$ was used as the gas-phase medium and the liquid-phase medium was prepared by adding $\mathrm{Mn}^{2+}, \mathrm{Fe}^{2+}$, SDS or $\mathrm{NaCl}$ solution into water. The oxidation absorption tower is a customized cylindrical absorption column with a volume of $40 \mathrm{~L}$. The inlet flow rate of micro bubbles generator is $12 \mathrm{~L} / \mathrm{min}$. The air intake volume is $2 \mathrm{~L} / \mathrm{min}$ and the water inlet pressure is $0.2 \mathrm{MPa}$. After 3-min stable operation, the concentrations of $\mathrm{NO}_{3}{ }^{-}$and $\mathrm{NO}_{2}{ }^{-}$were determined to calculate $\mathrm{NO}$ removal rates.

\section{Methods}

Air/ $\mathrm{O}_{3}$ and $\mathrm{NO}$ were mixed according to different proportions and then added into the micro bubble generator together with the absorption liquid to prepare MBGLS, which was sprayed into the oxidation-absorption tower, where MBs gradually collapsed and disappeared so that the NO absorption process was completed. In the process, nitrate nitrogen, nitrite nitrogen, and hydroxyl radical in the solution in the oxidation absorption tower were measured by the steady-state/transient fluorescence spectrometer and the UV absorption spectrophotometry to calculate denitration rates.

The effects of NO intake (1250 ppm, $2500 \mathrm{ppm}$, $3750 \mathrm{ppm}, 5000 \mathrm{ppm}$, and $6250 \mathrm{ppm}), \mathrm{O}_{3}$ intake $(1675 \mathrm{ppm}$, $2500 \mathrm{ppm}, 5000 \mathrm{ppm}, 10,000 \mathrm{ppm}$, and 15,000 ppm), pH
(3, 5, 7, 9 and 11$), \mathrm{NaCl}$ concentrations $(0.1 \mathrm{~g} / \mathrm{L}, 0.3 \mathrm{~g} / \mathrm{L}$, $0.5 \mathrm{~g} / \mathrm{L}, 0.7 \mathrm{~g} / \mathrm{L}$, and $0.9 \mathrm{~g} / \mathrm{L})$, SDS concentrations $(2 \mathrm{mg} / \mathrm{L}$, $4 \mathrm{mg} / \mathrm{L}, 6 \mathrm{mg} / \mathrm{L}$, and $8 \mathrm{mg} / \mathrm{L}$ ), and transition metal ion concentrations $(0.5 \mathrm{mmol} / \mathrm{L}, 1 \mathrm{mmol} / \mathrm{L}, 2 \mathrm{mmol} / \mathrm{L}, 3 \mathrm{mmol} / \mathrm{L}$, and $4 \mathrm{mmol} / \mathrm{L}$ ) on NO oxidation-absorption efficiency in the MBGLS were explored. Afterwards, the mechanism of NO oxidation-absorption by MBs oxidization process was elaborated.

\section{. $\mathrm{OH}$ test}

First, an excess of terephthalic acid (TA) was added into a colorimetric tube and directly passed through the newly generated $25 \mathrm{~mL}$ of MBs. The $\cdot \mathrm{OH}$ immediately reacted with TA to form 2-hydroxyterephthalic acid when the micron bubble broke. After $3 \mathrm{~min}$, the bubbles in the colorimetric tube disappeared and the test was performed with the steadystate/transient fluorescence spectrometer.<smiles>O=C(O)c1ccc(C(=O)O[Sn+]c2cc(C(=O)O)ccc2C(=O)O)cc1</smiles>

The capture agent TA is not a fluorescent agent and TAOH has a strong absorption peak at an excitation spectrum of $325 \mathrm{~nm}$ and an emission wavelength of $415 \mathrm{~nm}$ [31]. TA captures hydroxyl radicals to form TAOH. The content 
of hydroxyl radicals was determined by a fluorescence spectrometer.

\section{NO removal rate calculation method}

MBs gradually collapsed and disappeared after a certain period, so that the NO removal process was completed in the oxidation-absorption tower (Fig. 1j). In this study, the concentrations of $\mathrm{NO}_{2}{ }^{-}$and $\mathrm{NO}_{3}{ }^{-}$in the absorption solution were determined by the UV absorption spectrophotometer.

In the experiment, $\mathrm{NO}_{2}{ }^{-}$was not detected in the absorption solution, so the NO removal rate was calculated with the increase in the quantity of $\mathrm{NO}_{3}{ }^{-}$in the absorption system. The NO removal rate is calculated as follows:

$h=c_{1} \times q_{1} \times t / m_{1} \times 100 \%$,

$m_{1}=(M \times A / 22.4) \times[273 /(273+T)] \times P_{1} / P_{2} \times 10^{-6} \times q_{2} \times t$,

where $h$ is the NO removal rate, \%; $c_{1}$ is the mass concentration of $\mathrm{NO}_{3}{ }^{-}$in $N$ in the absorption liquid, $\mathrm{mg} / \mathrm{L} ; q_{1}$ is the inflow, $\mathrm{L} / \mathrm{min} ; t$ is the system running time, $\min ; m_{1}$ is the mass of intake NO (in $N) ; M$ is the molar mass of $N(\mathrm{~g} / \mathrm{mol})$ and the molar volume of gas under standard conditions is $22.4 \mathrm{~L} / \mathrm{mol} ; A$ is NO gas volume fraction, ppm; $T$ is room temperature, ${ }^{\circ} \mathrm{C} ; P_{1}$ is the pressure after gas depressurization, $\mathrm{Pa} ; \mathrm{P}_{0}$ is the atmospheric pressure, $\mathrm{Pa} ; q_{2}$ is the gas flow rate, $\mathrm{mL} / \mathrm{min}$; $t$ is the system running time, $\min$.

\section{Statistical analysis}

Experimental data were analyzed in Statistical Product and Service Solutions 19.0. One-way analysis of variance with a 95\% confidence interval and Dennett's post-test was used to determine whether the significant differences between the mean of the pristine group and the mean of each experimental group $(n=3, P<0.05)$.

\section{Results and discussion}

\section{Proposed reaction pathways}

In the widely concerned advanced oxidation processes (AOPs) for the removal of $\mathrm{NO}_{x}$ from flue gas, the transition-metal and $\cdot \mathrm{OH}$ serve as effective oxidants [32]. $\mathrm{Fe}^{2+}$ and $\mathrm{Mn}^{2+}$ ions activate $\mathrm{MBs}$, which can generate $\cdot \mathrm{OH}$ as the main oxidant for the conversion of NO [17]. Hence, NO removal in aqueous solutions is also thought to be dependent on the consumption of dissolved NO by various reactive species generated after MBs' breakage, thus maintaining the driving force required for the absorption process. The detailed proposed pathways for the MBGLS are illustrated in Fig. 2.

As shown in Fig. 2, the chemistry of NO consumption by MBGLS is complex, since it takes place through direct electron transfer in the free radical oxidation reactions via $\cdot \mathrm{OH}$, and the direct reaction of the $\mathrm{NO}_{\mathrm{x}}$ species with $\mathrm{O}_{3}$, $\mathrm{Mn}^{2+}$ and $\mathrm{Fe}^{2+}$. The main reactions involved in the oxidation and absorption of $\mathrm{NO}$ are provided as follows:

$\mathrm{O}_{3} \rightarrow \mathrm{O}+\mathrm{O}_{2}$,

$\mathrm{O}+\mathrm{H}_{2} \mathrm{O} \rightarrow \cdot \mathrm{OH}$

$\cdot \mathrm{OH}+\mathrm{NO} \rightarrow \mathrm{H}^{+}+\mathrm{NO}_{2}^{-}$,

$\cdot \mathrm{OH}+\mathrm{NO}_{2} \rightarrow \mathrm{NO}_{3}^{-}+\mathrm{H}^{+}$,

$\cdot \mathrm{OH}+\mathrm{NO}_{2}^{-} \rightarrow \mathrm{NO}_{2}+\mathrm{OH}^{-}$,

$2 \mathrm{NO}+2 \mathrm{O}_{3} \rightarrow \mathrm{NO}_{2}+3 \mathrm{O}_{2}$,

$3 \mathrm{NO}_{2}+\mathrm{H}_{2} \mathrm{O} \rightarrow 2 \mathrm{HNO}_{3}+\mathrm{NO}$,

$\mathrm{Fe}^{2+}+\mathrm{O}_{3} \rightarrow \mathrm{Fe}^{3+}+\mathrm{O}_{3}^{-}$,

$\mathrm{Mn}^{2+}+\mathrm{O}_{3} \rightarrow \mathrm{Mn}^{3+}+\mathrm{O}_{3}^{-}$,

$\mathrm{O}_{3}^{-}+\mathrm{H}^{+} \rightarrow \cdot \mathrm{OH}$,

$\mathrm{Fe}^{2+}+\mathrm{O}_{3} \rightarrow \mathrm{FeO}^{2+}+\mathrm{O}_{2}$,

$\mathrm{FeO}^{2+}+\mathrm{H}_{2} \mathrm{O} \rightarrow \mathrm{Fe}^{3+}+\cdot \mathrm{OH}+\mathrm{OH}^{-}$,

$\mathrm{Mn}^{2+}+\mathrm{O}_{3}+\mathrm{H}_{2} \mathrm{O} \longrightarrow \mathrm{MnO}_{2}+\mathrm{O}_{2}+2 \mathrm{H}^{+}$.

\section{Mechanism of NO by oxidative absorption of MBs}

Figure 3 shows the result of $\cdot \mathrm{OH}$ measured by the steadystate/transient fluorescence spectrometer. The content of hydroxyl radicals in MBGLS is much higher than that in water, indicating that MBs activate dissolved oxygen in water, generate hydroxyl radicals, and finally increase the NO oxidation efficiency. This, residence time of MBs in the liquid phase is prolonged and the mass transfer between gas and liquid is enhanced. 


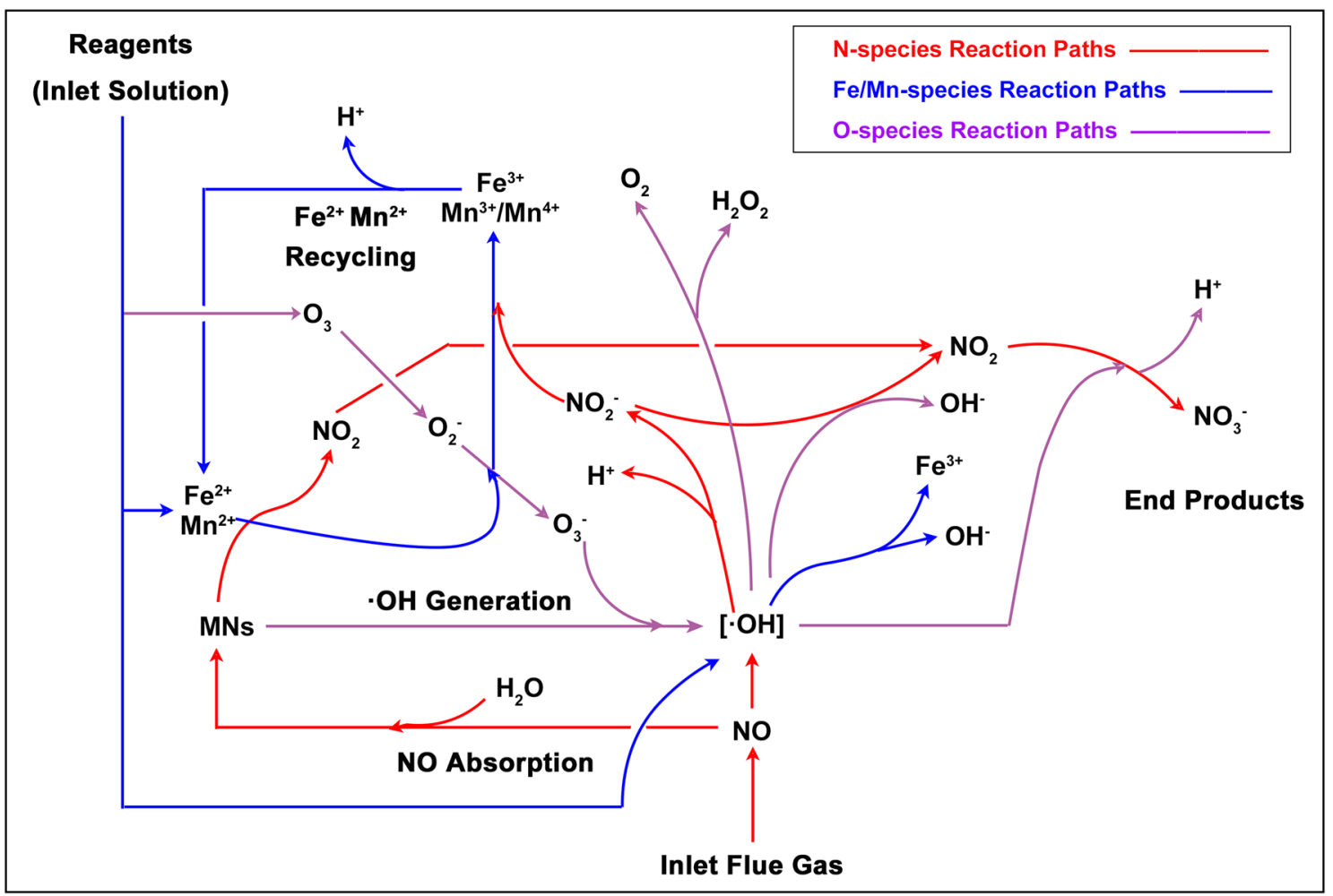

Fig. 2 Schematic diagram of the MBGLS

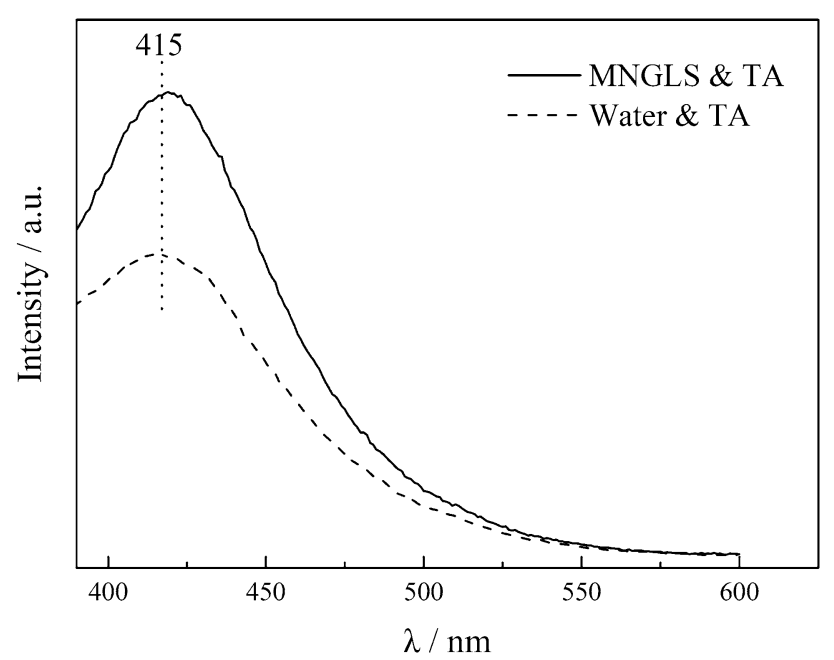

Fig. 3 Fluorescence diagram of TAOH

\section{Effects of transition metal ions on NO removal rate}

To determine the effects of transition metal ionic concentration on NO removal rate, we prepared influent solutions with different $\mathrm{Mn}^{2+}\left(\right.$ or $\mathrm{Fe}^{2+}$ ) concentrations $(0.5 \mathrm{mmol} / \mathrm{L}$, $1 \mathrm{mmol} / \mathrm{L}, 2 \mathrm{mmol} / \mathrm{L}, 3 \mathrm{mmol} / \mathrm{L}$, and $4 \mathrm{mmol} / \mathrm{L}$ ) and different $\mathrm{Mn}^{2+} / \mathrm{Fe}^{2+}$ ratios $(0.5,1,2,3$ and 4). Then, we determined the concentrations of $\mathrm{NO}_{3}{ }^{-}$and $\mathrm{NO}_{2}{ }^{-}$in the oxidation-absorption tower to calculate NO removal rates. After the addition of $\mathrm{Fe}^{2+}$ and $\mathrm{Mn}^{2+}$, when the ion concentration in MBGLS was increased below $2 \mathrm{mmol} / \mathrm{L}$, the removal rate was significantly improved (Fig. 4). Free radicals oxidized Fe [II] and Mn [II] into Fe [III], Mn [III], and oxygen radicals after the addition of $\mathrm{Fe}^{2+}$ and $\mathrm{Mn}^{2+}$ in the liquid phase. Therefore, Fe [III] and Mn [III] oxidized $\mathrm{NO}$ into $\mathrm{NO}_{2}$ as a catalyst to accelerate the removal of NO. When the ion concentration was $2 \mathrm{mmol} / \mathrm{L}$, the $\mathrm{NO}$ removal rate reached $63.4 \%$. When the ion concentration further increased above $2 \mathrm{mmol} / \mathrm{L}$, the NO removal rate decreased. Both $\mathrm{Fe}^{2+}$ and $\mathrm{Mn}^{2+}$ at higher concentrations were hydrolyzed, and fine particles produced by hydrolysis were found adhered to the gas surface. It was difficult for flue gas inside bubbles to interact with hydroxyl radicals in the liquid phase, thus resulting in a decrease in the efficiency. Transition metal ions could react with $\mathrm{O}_{3}$ molecules to produce $\cdot \mathrm{O}_{3}{ }^{-}$, thus leading to a chain reaction producing $\cdot \mathrm{OH}$, as indicated in Eqs. (4) and (5).

Under the same conditions, after the addition of metal ions, the removal rate of $\mathrm{NO}$ obtained after adding $\mathrm{Mn}^{2+}$ was higher than that obtained after the addition of $\mathrm{Fe}^{2+}$ (Fig. 4). The difference may be interpreted as follows: The catalytic ability of $\mathrm{Mn}^{2+}$ is stronger than that of $\mathrm{Fe}^{2+}$. According to Eqs. (11)-(16), the potential of $\mathrm{Mn}^{3+} / \mathrm{Mn}^{2+}$ is $1.5 \mathrm{~V}$ higher 


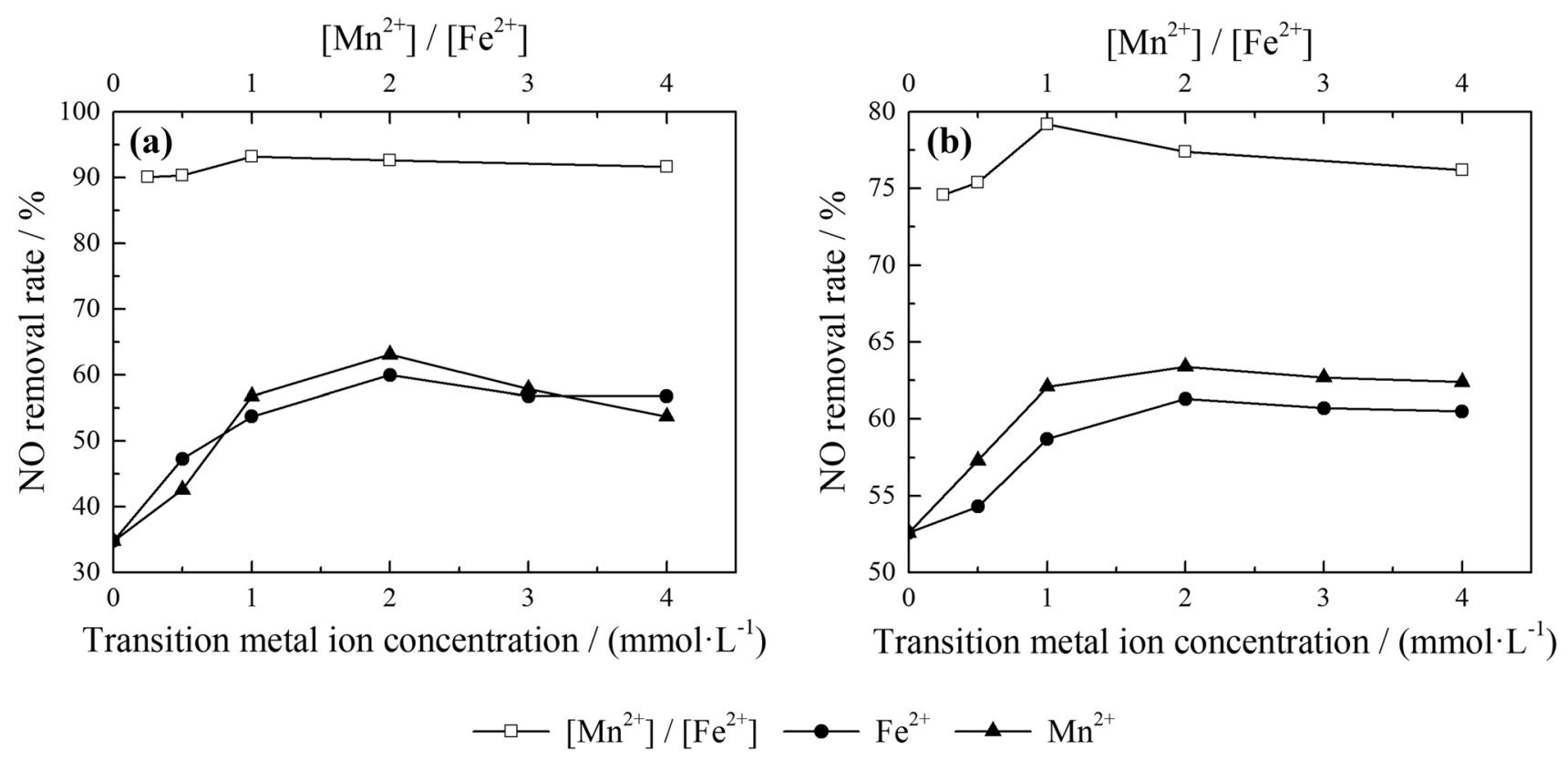

Fig. 4 Effects of transition metal ion concentration on NO removal efficiency (reaction conditions: a NO concentration $=3750$ ppm, $\mathrm{O}_{3}$ concentration $=0 ; \mathbf{b} \mathrm{O}_{3}$ concentration $=2500 \mathrm{ppm}, \mathrm{NO}$ concentration $=5000 \mathrm{ppm}$ )

than that of $\mathrm{Fe}^{3+} / \mathrm{Fe}^{2+}(0.77 \mathrm{~V})$ [33]. Moreover, $\mathrm{Fe}^{2+}$ is easier to be hydrolyzed than $\mathrm{Mn}^{2+}$ and the mass transfer efficiency is reduced.

When the metal ion concentration was low, $\mathrm{O}_{3}$ molecules and metal ions were combined to produce hydroxyl radicals through chain reactions. The hydroxyl radicals oxidized NO into nitrogen oxides, which were then easily absorbed. Therefore, NO removal rate was increased. When the concentration of metal ions was greater than $2 \mathrm{mmol} / \mathrm{L}$, the $\mathrm{O}_{3}$ molecules decomposed faster and generated more oxygen. At this point, the dissolved oxygen solution was saturated and the NO removal rate does not increase.

When $\mathrm{Mn}^{2+} / \mathrm{Fe}^{2+}$ concentration ratio was 1 , the NO removal rate was up to $93.2 \%$, which was $30.1 \%$ higher than that obtained after the addition of $\mathrm{Mn}^{2+}$ alone, and $33.2 \%$ higher than that obtained after the addition of $\mathrm{Fe}^{2+}$ alone. This proved that $\mathrm{Mn}^{2+}$ and $\mathrm{Fe}^{2+}$ showed the synergistic effect on the catalytic NO oxidation removal. In the experiment, when more $\mathrm{Fe}^{2+}$ was added, the hydrolysis degree of $\mathrm{Fe}^{2+}$ was aggravated. At this stage, the solution turned into a red-brown turbid liquid, thus hindering the contact of NO with ozone and decreasing NO removal rate.

\section{Effects of pH on NO removal rate}

To determine the effects of $\mathrm{pH}$ on NO removal rate, we prepared influent solutions with different $\mathrm{pH}$ values $(3,5,7$, 9 and 11) and determined the concentrations of $\mathrm{NO}_{3}{ }^{-}$and $\mathrm{NO}_{2}{ }^{-}$in the oxidation-absorption tower to calculate $\mathrm{NO}$ removal rates. When $\mathrm{pH}$ increased below 5, NO removal rate increased (Fig. 5). When the $\mathrm{pH}$ further increased above 5 , NO removal rate decreased. With the addition of $\mathrm{Fe}^{2+}$ or $\mathrm{Mn}^{2+}$ ions, the NO removal rate increased. When the $\mathrm{pH}$ was low, due to the high acidity of the liquid phase, $\mathrm{OH}^{-}$accumulated on the surface of the MBs was consumed, thus resulting in the decreased surface charge on the MBs. Bubbles ruptured easily and gas-liquid contact time was decreased, thus eventually resulting in the decreased NO removal rate. Therefore, when the $\mathrm{pH}$ was close to 5 , dissolved oxygen in water was also relatively high, thus promoting the oxidation of $\mathrm{NO}$ into $\mathrm{NO}_{2} . \mathrm{Fe}^{2+}$ and $\mathrm{Mn}^{2+}$ were greatly hydrolyzed in water, thus resulting in turbidity in the liquid phase and affecting the gas-liquid mass transfer. Ion hydrolysis decreased the ion concentration and eventually affected the ion catalysis efficiency. Under the condition of higher $\mathrm{pH}$, the oxidation potential of reactive oxygen species became lower and the negative charges carried on the surface of the bubbles were easily repelled from the $\mathrm{OH}^{-}$ions in the solution, thus increasing bubble movements in water as well as the probability of bubble collision. Therefore, it eventually led to the rupture of bubbles, affected bubble residence time, and decreased NO oxidization and absorption.

The stability of ozone in water was strongly influenced by $\mathrm{pH}$ in $\mathrm{O}_{3}$ MBGLS. At lower $\mathrm{pH}$, ozone decomposed more slowly in water. Ozone molecules were oxidized and NO removal rate also increased. When the $\mathrm{pH}$ value was lower than 5, since the oxidation-reduction potential of $\mathrm{O}_{3}$ was lower than that of $\cdot \mathrm{OH}, \mathrm{NO}$ removal rate was not high. As the solution $\mathrm{pH}$ increased, $\mathrm{O}_{3}$ reacted with $\mathrm{OH}^{-}$to form hydroxyl radicals and the NO removal rate increased. When 

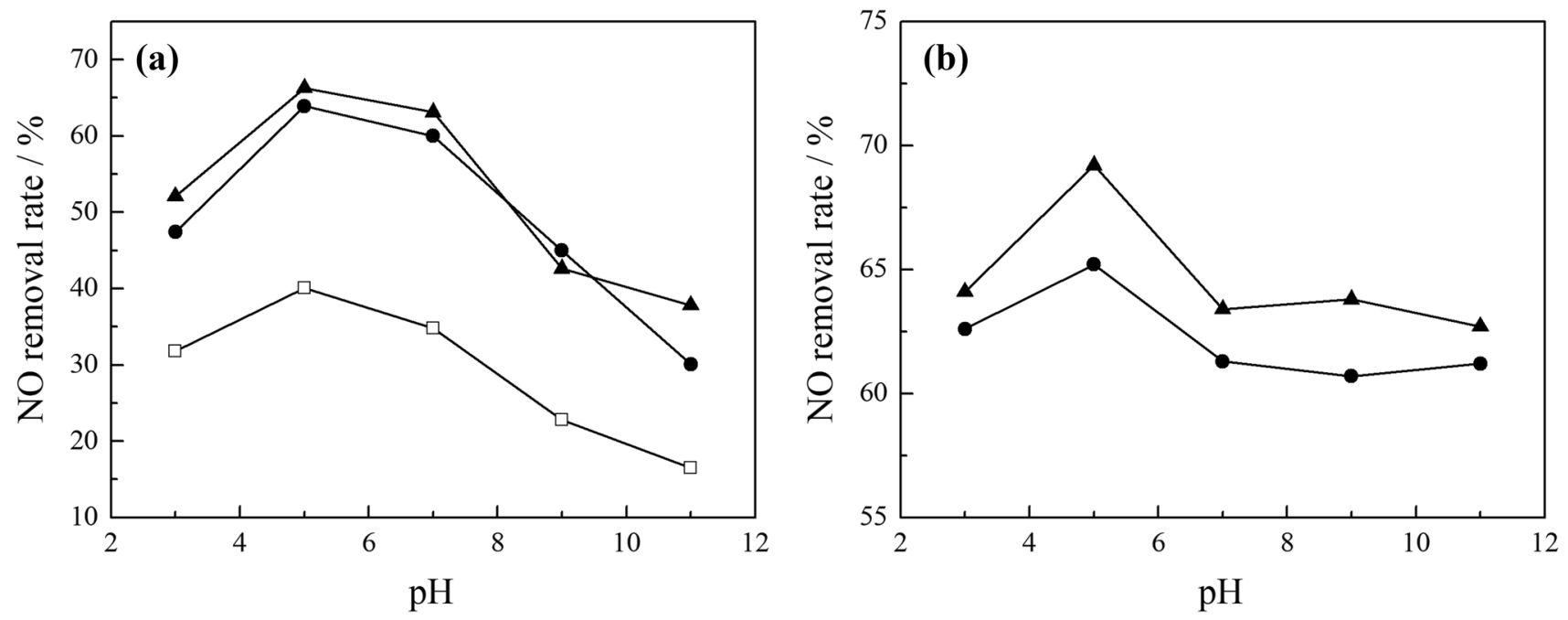

$\multimap \mathrm{Fe}^{2+} \longrightarrow \mathrm{Mn}^{2+} \longrightarrow$ Control

Fig. 5 Effects of $\mathrm{pH}$ on $\mathrm{NO}$ removal efficiency (reaction conditions: a $\mathrm{NO}$ concentration $=3750 \mathrm{ppm}, \mathrm{O}_{3}$ concentration $=0$; b $\mathrm{O}_{3}$ concentration $=2500 \mathrm{ppm}$, NO concentration $=5000 \mathrm{ppm}$ )

the solution was alkaline, $\mathrm{Fe}^{2+}$ and $\mathrm{Mn}^{2+}$ were greatly hydrolyzed in water and the oxidization ability of reactive oxygen was decreased, thus decreasing the NO removal rate.

\section{Effects of $\mathrm{NaCl}$ and $\mathrm{pH}$ concentration on $\mathrm{NO}$ removal rate}

To determine the effects of $\mathrm{NaCl}$ concentration on $\mathrm{NO}$ removal rate, we prepared influent solutions with different $\mathrm{NaCl}$ concentrations $(0.1 \mathrm{~g} / \mathrm{L}, 0.3 \mathrm{~g} / \mathrm{L}, 0.5 \mathrm{~g} / \mathrm{L}, 0.7 \mathrm{~g} / \mathrm{L}$ and $0.9 \mathrm{~g} / \mathrm{L}$ ) and determined the concentrations of $\mathrm{NO}_{3}{ }^{-}$and $\mathrm{NO}_{2}{ }^{-}$in the oxidation-absorption tower to calculate $\mathrm{NO}$ removal rates. As shown in Fig. 6a, with the increase in $\mathrm{NaCl}$ concentration, $\mathrm{NO}$ removal rate gradually increases. When the $\mathrm{NaCl}$ concentration was $0.5 \mathrm{~g} / \mathrm{L}$, NO removal rates under three conditions $\left(\mathrm{Mn}^{2+}, \mathrm{Fe}^{2+}\right.$, and control without catalyst) were, respectively, $75.8 \%, 83.2 \%$, and $47.4 \%$. As the salinity of the solution increased, dissolved oxygen increased and peaked under a $\mathrm{NaCl}$ concentration of 500 MBG/L (Fig. 6b). The result was consistent with experimental results. When the $\mathrm{NaCl}$ concentration further increased, the NO absorptivity decreased. As the hydration energy of $\mathrm{Na}^{+}(-406 \mathrm{~kJ} / \mathrm{mol})$ is close to that of $\mathrm{CI}^{-}(-317 \mathrm{~kJ} / \mathrm{mol})$, under the low $\mathrm{NaCl}$ concentration $(0.1-0.5 \mathrm{~g} / \mathrm{L}), \mathrm{OH}^{-}$ions on bubble surface are combined with $\mathrm{Na}^{+}$ions. Therefore, the zeta potential of bubbles decreases and the gas-liquid oxygenation rate is increased. In this way, NO removal rate increases. An appropriate salinity increases liquid viscosity and bubble surface tension, enhances bubble stability, and extends residence time in water. With the increase in $\mathrm{NaCl}$ concentration, $\mathrm{Cl}^{-}$is gradually accumulated on bubble surface, thus increasing gas dissolution resistance and decreasing NO removal rate.

To determine the effects of SDS concentration on NO removal, we prepared influent solutions with different SDS concentrations $(2 \mathrm{mg} / \mathrm{L}, 4 \mathrm{mg} / \mathrm{L}, 6 \mathrm{mg} / \mathrm{L}$ and $8 \mathrm{mg} / \mathrm{L})$ and determined the concentrations of $\mathrm{NO}_{3}{ }^{-}$and $\mathrm{NO}_{2}{ }^{-}$in the oxidation-absorption tower to calculate $\mathrm{NO}$ removal rates. NO removal rate increased with the increase in SDS concentration (Fig. 6). At the SDS concentration of $6 \mathrm{mg} / \mathrm{L}$, when $\mathrm{Mn}^{2+}$ and $\mathrm{Fe}^{2+}$ were, respectively, added to the system, the NO removal rates reached $82.1 \%$ and $92.3 \%$, respectively. However, when the SDS concentration was further increased, the NO removal rate decreased. After the addition of the surfactant (SDS) in water, the resulting MB size was significantly reduced. With the increase in SDS concentration, the bubble size decreased and the internal pressure of bubbles increased. The energy released at the moment of bubble rupturing produced a large number of free radicals, which accelerated oxidation and absorption of NO. When the SDS concentration was too high, the bubble size was too small and the stability was weakened. Residence time in water phase was too short and not conducive to the gas-liquid contact, thus resulting in the slightly decreased NO removal rate.

Smaller bubbles indicate the larger specific surface area and the larger gas-liquid contact area. $\mathrm{O}_{3}$ generated by ozone decomposition is beneficial to the gas-liquid exchange, as it can accelerate the chain reaction rate of $\cdot \mathrm{OH}$, generate more free radicals, and promote the oxidative absorption of NO. In addition, smaller bubbles indicate the greater pressure inside bubbles and the more energy released when rupturing. 

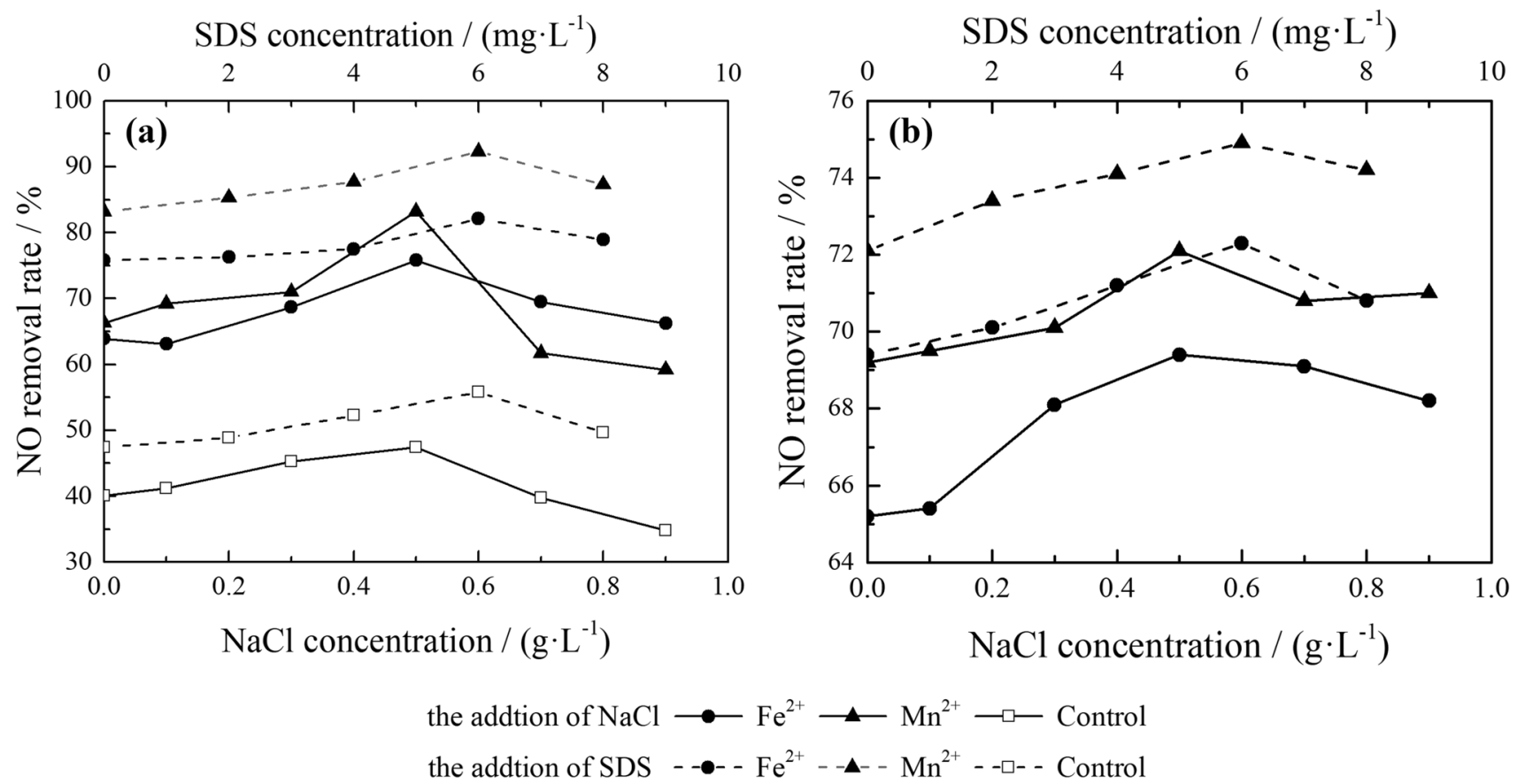

Fig. 6 Effects of $\mathrm{NaCl}$ and $\mathrm{pH}$ concentration on $\mathrm{NO}$ removal efficiency (reaction conditions: a $\mathrm{NO}$ concentration $=3750 \mathrm{ppm}, \mathrm{O}_{3}$ concentration $=0 ; \mathbf{b ~ O}_{3}$ concentration $=2500 \mathrm{ppm}, \mathrm{NO}$ concentration $=5000 \mathrm{ppm}$ )

Therefore, it increases molecular movement and NO removal rate.

\section{Effects of NO concentration on NO removal rate}

To determine the effects of inlet flow rate on NO removal rate, we prepared the inlet gas with different $\mathrm{NO}$ concentrations (1250 ppm, $2500 \mathrm{ppm}, 3750 \mathrm{ppm}, 5000 \mathrm{ppm}$ and
$6250 \mathrm{ppm})$. Then, we determined the concentrations of $\mathrm{NO}_{3}{ }^{-}$and $\mathrm{NO}_{2}{ }^{-}$in the oxidation-absorption tower to calculate NO removal rates. Figure 7 a shows the effects of NO concentration on $\mathrm{NO}$ removal rate. The $\mathrm{NO}$ removal rate decreased as the NO intake flow rate increased. However, after $\mathrm{Fe}^{2+}$ and $\mathrm{Mn}^{2+}$ ions were ,respectively, added, the removal rate of $\mathrm{NO}$ at a concentration of $1250 \mathrm{ppm}$ reached $100 \%$, which was $50 \%$ higher than that obtained without the
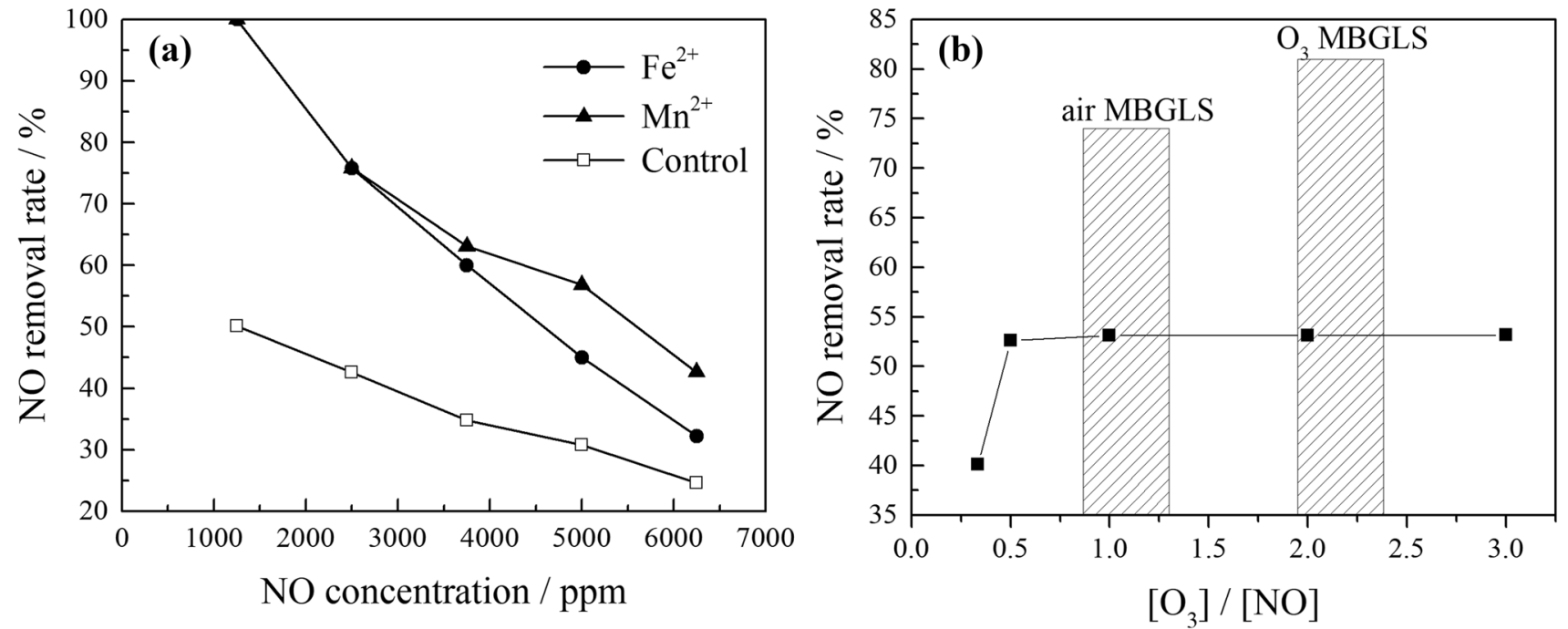

Fig. 7 Effects of flow rate on NO removal efficiency (reaction conditions: $\mathbf{a} \mathrm{O}_{3}$ concentration $=0$; $\mathbf{b}$ NO concentration $=5000 \mathrm{ppm}$ ) 
addition of $\mathrm{Fe}^{2+}$ and $\mathrm{Mn}^{2+}$ ions. Compared with $\mathrm{NO}$ removal rate in the conventional bubble column, the $\mathrm{NO}$ removal rate in MBGLS was significantly increased. NO is extremely difficult to be dissolved in water. According to the double-film theory, the dissolution process of $\mathrm{NO}$ in water is controlled by a liquid film. $\mathrm{NO}_{2}$ as the oxidation product of $\mathrm{NO}$, is soluble in water and its dissolution process is controlled by the gas film. With the increase in NO concentration, the mass transfer efficiency between $\mathrm{NO}$ and liquid phase did not change greatly [34]. Therefore, the NO removal rate decreased with the increase in NO concentration. However, after transition metal ions such as $\mathrm{Fe}^{2+}$ and $\mathrm{Mn}^{2+}$ were, respectively, added into the absorption liquid, they made the reaction faster as they played a catalytic role in the reaction by generating the free radical chain (Eqs. (11)-(16)). Therefore, hydroxyl radicals oxidized NO at a much faster rate. The removal rate of $\mathrm{NO}$ increased significantly after the addition of transition metal ions.

When $\left[\mathrm{O}_{3}\right] /[\mathrm{NO}]$ was 0.5 , NO removal rate reached $52.6 \%$ (Fig. 7b). With the increase in $\left[\mathrm{O}_{3}\right] /[\mathrm{NO}]$ (more than 0.5 ), the NO removal rate increased slightly. In the gas phase, NO was oxidized by $\mathrm{O}_{3}$ into high-valence $\mathrm{NO}_{x}$, such as $\mathrm{NO}_{2}$. The high-valence $\mathrm{NO}_{x}$ became soluble in water to form nitric acid. As indicated in Eq. (9), the most suitable mole ratio of $\left[\mathrm{O}_{3}\right] /[\mathrm{NO}]$ for the oxidation reaction between $\mathrm{NO}$ and $\mathrm{O}_{3}$ is 1 . However, according to Eqs. (4)-(9), oxygen atom produced by ozone decomposition activates water into hydroxyl radicals. Therefore, hydroxyl radicals reacted with NO to generate $\mathrm{NO}_{2}$ and reduced the ozone consumption. Bubbles ruptured and generated free radicals, thus enhancing NO oxidation and absorption. According to Eqs. (4)-(10), with the increase in $\left[\mathrm{O}_{3}\right] /[\mathrm{NO}]$, a large amount of nitric acid accumulates in the solution, thus resulting in a drop in the $\mathrm{pH}$ of the solution. When $\left[\mathrm{O}_{3}\right] /[\mathrm{NO}]$ was larger than 1 , the dissolution of $\mathrm{NO}_{2}$ was limited, but the removal rate of $\mathrm{NO}$ was not greatly affected.

MBs were generated with air $/ \mathrm{O}_{3}$ and water. The denitration efficiency of the two MBGLS was compared under the same conditions. The parameters of the air MBGLS are provided as follows: $5000 \mathrm{ppm} \mathrm{NO}, \mathrm{pH} 5,0.5 \mathrm{~g} / \mathrm{L} \mathrm{NaCl}, 6 \mathrm{mg} / \mathrm{L}$ SDS and $\left[\mathrm{Mn}^{2+} / \mathrm{Fe}^{2+}\right]=1$ (concentrations of both metal ions were $2 \mathrm{mmol} / \mathrm{L}$ ). For $\mathrm{O}_{3} \mathrm{MBGLS}$, the ratio of $\mathrm{O}_{3}$ and $\mathrm{NO}$ was 0.5 and the other conditions were the same. Under these conditions, $\mathrm{NO}$ oxidization and absorption performances of $\mathrm{O}_{3}$ and air MBGLS were compared (Fig. 7b).

As shown in Fig. 7b, under the optimal conditions, the NO removal rate in $\mathrm{O}_{3}$ MBGLS is significantly higher than that of the air MBGLS. The difference may be interpreted as follows: First, in $\mathrm{O}_{3}$ MBGLS, the ozone oxidation process of NO can be divided into two steps. In the first step, $\mathrm{NO}$ is oxidized by ozone to $\mathrm{NO}_{2}$ in the interior of the MBs (gas phase). In the second step, free radicals are generated by ozone decomposition in water, partial NO in the liquid phase is oxidized into $\mathrm{NO}_{2}$ and eventually absorbed by the liquid. Similarly, in the air MBGLS, there are two oxidation processes. In the first step, oxygen has lower oxidation performance than ozone. In the second step, compared with ozone MBGLS, air MBGLS do not generate extra free radicals (except free radicals generated when bubbles burst). In summary, under the same conditions, the removal of nitrogen oxides by the ozone MBGLS proved to be much better than that of the air MBGLS.

\section{Conclusions}

This study demonstrates the feasibility of the efficient removal of NO from flue gas with the air/ $\mathrm{O}_{3}$ MBGLS. The effects of $\mathrm{O}_{3}$ concentration, transition metal ion concentration, $\mathrm{pH}, \mathrm{NaCl}$ concentration, $\mathrm{SDS}$ concentration, $\mathrm{Mn}^{2+}$ to $\mathrm{Fe}^{2+}$ ratio, and other factors on $\mathrm{NO}$ removal rate were explored. MNBLS can effectively remove NO, realize the synergistic desulfurization and denitrification and reduce various pollution gases such as VOCs in the future. The conclusions are stated below.

In the air and NO MBGLS (1250 ppm NO and pH 7), the NO removal rate reached $50.1 \%$. Under $3750 \mathrm{ppm}$ NO, after $\mathrm{Fe}^{2+}$ and $\mathrm{Mn}^{2+}$ ions were, respectively, added, the removal rates, respectively, reached $60.0 \%$ and $63.1 \%$. Under the conditions of $3750 \mathrm{ppm} \mathrm{NO}, \mathrm{pH} 7,0.5 \mathrm{~g} / \mathrm{L} \mathrm{NaCl}$, and $6 \mathrm{mg} / \mathrm{L}$ SDS, when $2 \mathrm{mmol} / \mathrm{L} \mathrm{Fe}^{2+}$ and $2 \mathrm{mmol} / \mathrm{L} \mathrm{Mn}^{2+}$ ions were, respectively, added, the NO removal rates reached $82.1 \%$ and $92.3 \%$, respectively. When the metal ion ratio $\left[\mathrm{Mn}^{2+} / \mathrm{Fe}^{2+}\right]$ was 1 , the highest NO removal rate of the system was $93.2 \%$.

In $\mathrm{O}_{3}$ and NO MBGLS, NO oxidation was better than that in air and NO MBGLS. When $\left[\mathrm{O}_{3}\right] /[\mathrm{NO}]$ was 0.5 , the $\mathrm{NO}$ removal rate reached $52.6 \%$. When $2 \mathrm{mmol} / \mathrm{L} \mathrm{Fe}^{2+}$ and $2 \mathrm{mmol} / \mathrm{L} \mathrm{Mn}^{2+}$ were, respectively, added into the $\mathrm{O}_{3}$ and NO MBGLS, the NO removal rates reached $61.3 \%$ and $63.4 \%$, respectively. At $\mathrm{pH} 5$, when $\mathrm{Fe}^{2+}$ and $\mathrm{Mn}^{2+}$ were, respectively, added, the NO removal rates were calculated to be $65.2 \%$ and $69.2 \%$, respectively. Under $0.5 \mathrm{~g} / \mathrm{L} \mathrm{NaCl}$, when $\mathrm{Fe}^{2+}$ and $\mathrm{Mn}^{2+}$ were, respectively, added, NO removal rates reached $69.4 \%$ and $72.1 \%$, respectively. Under $6 \mathrm{mg} / \mathrm{L} \mathrm{SDS}$, when $\mathrm{Fe}^{2+}$ and $\mathrm{Mn}^{2+}$ were, respectively, added, NO removal rates reached $72.3 \%$ and $74.9 \%$, respectively. $\mathrm{O}_{3}$ MBGLS was better than air MBGLS. However, in both systems, the influences of various factors on NO removal efficiency was basically the same.

$\mathrm{Mn}^{2+}$ and $\mathrm{Fe}^{2+}$ exhibited a synergistic effect on the catalytic $\mathrm{NO}$ oxidation and removal. After the addition of $\mathrm{Fe}^{2+}$ and $\mathrm{Mn}^{2+}$ in the liquid phase, free radicals were generated due to MBs rupturing and converted $\mathrm{Fe}$ [II] and $\mathrm{Mn}$ [II] into Fe [III] and $\mathrm{Mn}[\mathrm{III}]$. Therefore, $\mathrm{Mn}^{2+}$ and $\mathrm{Fe}^{2+}$ acted as a catalyst to accelerate $\mathrm{NO}$ removal. Appropriate $\mathrm{NaCl}$ concentration increased the liquid viscosity, bubble surface 
tension, bubble stability, and residence time in water. The addition of SDS decreased the bubble size and increased the internal pressure. When the MBs burst, the instantaneous energy released generated a large amount of free radicals, which accelerated oxidation and removal of NO.

Acknowledgements This work was supported by the National Natural Science Foundation of China (Grant number U1660107).

\section{Compliance with ethical standards}

Conflict of interest The authors declare no competing financial interest.

Open Access This article is licensed under a Creative Commons Attribution 4.0 International License, which permits use, sharing, adaptation, distribution and reproduction in any medium or format, as long as you give appropriate credit to the original author(s) and the source, provide a link to the Creative Commons licence, and indicate if changes were made. The images or other third party material in this article are included in the article's Creative Commons licence, unless indicated otherwise in a credit line to the material. If material is not included in the article's Creative Commons licence and your intended use is not permitted by statutory regulation or exceeds the permitted use, you will need to obtain permission directly from the copyright holder. To view a copy of this licence, visit http://creativecommons.org/licenses/by/4.0/.

\section{References}

1. Attard P, Moody MP, Tyrrell JWG (2002) Nanobubbles: the big picture. Phys A 314(1):696-705. https://doi.org/10.1016/S0378 -4371(02)01191-3

2. Pérez Garibay R, Martínez Ramos E, Rubio J (2012) Gas dispersion measurements in microbubble flotation systems. Miner Eng 26(1):34-40. https://doi.org/10.1016/j.mineng.2011.10.006

3. Temesgen T, Bui TT, Han M, Kim TI, Park H (2017) Micro and nanobubble technologies as a new horizon for water-treatment techniques: a review. Adv Colloid Interface Sci 246:40-51. https ://doi.org/10.1016/j.cis.2017.06.011

4. Ushikubo FY, Furukawa T, Nakagawa R, Enari M, Makino Y, Kawagoe Y, Shiina T, Oshita S (2010) Evidence of the existence and the stability of nano-bubbles in water. Colloids Surf A 361(1):31-37. https://doi.org/10.1016/j.colsurfa.2010.03.005

5. Azevedo A, Etchepare R, Calgaroto S, Rubio J (2016) Aqueous dispersions of nanobubbles: generation, properties and features. Miner Eng 94:29-37. https://doi.org/10.1016/j.minen g.2016.05.001

6. Yang C, Dabros T, Li D, Czarnecki J, Masliyah JH (2001) Measurement of the zeta potential of gas bubbles in aqueous solutions by microelectrophoresis method. J Colloid Interface Sci 243(1):128-135. https://doi.org/10.1006/jcis.2001.7842

7. Takahashi $\mathrm{M}(2005) \zeta$ potential of microbubbles in aqueous solutions: electrical properties of the gas-water interface. J Phys Chem B 109(46):21858-21864. https://doi.org/10.1021/jp0445270

8. Li H, Hu L, Song D, Lin F (2014) Characteristics of micro-nano bubbles and potential application in groundwater bioremediation. Water Environ Res 86(9):844-851

9. Tada K, Maeda M, Nishiuchi Y, Nagahara J, Hata T, Zhuowei Z, Yoshida Y, Watanabe S, Ohmori M (2014) ESR measurement of hydroxyl radicals in micro-nanobubble water. Chem Lett 43(12):1907-1908. https://doi.org/10.1246/cl.140691

10. Yang W, Zhang R, Chen B, Duprez D, Royer S (2012) New aspects on the mechanism of $\mathrm{C}_{3} \mathrm{H}_{6}$ selective catalytic reduction of $\mathrm{NO}$ in the presence of $\mathrm{O}_{2}$ over $\mathrm{LaFe} 1-x(\mathrm{Cu}, \mathrm{Pd}) x \mathrm{O}_{3}-\delta$ perovskites. Environ Sci Technol 46(20):11280-11288. https://doi. org/10.1021/es302240m

11. Huaâ W, Ku Y, Shiâ Y, Chingâ Y (2007) Effect of sodium dodecyl sulfate (SDS) on bubble characteristics and ozone transfer in a bubble column. J Chin Inst Chem Eng 30(1):155-161. https://doi. org/10.1080/02533839.2007.9671239

12. Agarwal A, Ng WJ, Liu Y (2011) Principle and applications of microbubble and nanobubble technology for water treatment. Chemosphere 84(9):1175-1180. https://doi.org/10.1016/j.chemospher e.2011.05.054

13. Hu L, Xia Z (2018) Application of ozone micro-nano-bubbles to groundwater remediation. J Hazard Mater 342(15):446-453. https://doi.org/10.1016/j.jhazmat.2017.08.030

14. Honghui S, Xiyun J, Shufang W, Weihua G, Khaled SM, Kaihua L (2018) Effects of micro-nano bubble aerated irrigation and nitrogen fertilizer level on tillering, nitrogen uptake and utilization of early rice. Plant Soil Environ 64(7):297-302. https://doi. org/10.17221/240/2018-PSE

15. Jabesa A, Ghosh P (2017) Removal of dimethyl phthalate from water by ozone microbubbles. Environ Technol 38(16):20932103. https://doi.org/10.1080/09593330.2016.1246610

16. Wu Q, Sun C, Wang H, Wang T, Wang Y, Wu Z (2018) The role and mechanism of triethanolamine in simultaneous absorption of $\mathrm{NO}_{\mathrm{x}}$ and $\mathrm{SO}_{2}$ by magnesia slurry combined with ozone gas-phase oxidation. Chem Eng J 341(1):157-163. https://doi. org/10.1016/j.cej.2018.01.150

17. Adewuyi YG, Sakyi NY (2013) Simultaneous absorption and oxidation of nitric oxide and sulfur dioxide by aqueous solutions of sodium persulfate activated by temperature. Ind Eng Chem Res 52(33):11702-11711. https://doi.org/10.1021/ie401649s

18. Zhou Y, Li W, Zhang Q, Yan S, Cao Y, Dong F, Wang F (2017) Non-noble metal plasmonic photocatalysis in semimetal bismuth films for photocatalytic NO oxidation. Phys Chem Chem Phys 19(37):25610-25616. https://doi.org/10.1039/C7CP0 $4359 \mathrm{G}$

19. Jõgi I, Levoll E, Raud J (2016) Effect of catalyst placement on the plasma-catalytic oxidation of NO. Catal Lett 147(2):566-571. https://doi.org/10.1080/02533839.2007.9671239

20. Li S, Li K, Hao J, Ning P, Tang L, Wang C (2017) Simultaneous adsorption/oxidation of $\mathrm{NO}$ and $\mathrm{SO}_{2}$ over $\mathrm{Al}-\mathrm{Cu}$ composite metal oxides supported on MCM-41 at low temperature. J Chem Eng Jpn 50(5):376-382. https://doi.org/10.1252/jcej.15we131

21. Zhao Y, Wang H, Wang T (2016) Adsorption of NO from flue gas by molecularly imprinted adsorbents. Chem Eng J 306:832-839. https://doi.org/10.1016/j.cej.2016.08.023

22. Li H, Guo SJ, Shin K, Wong MS, Henkelman G (2019) Design of a Pd-Au nitrite reduction catalyst by identifying and optimizing active ensembles. ACS Catal 9(9):7957-7966. https://doi. org/10.1021/acscatal.9b02182

23. Zeng Y, Wang T, Zhang S, Wang Y, Zhong Q (2017) Sol-gel synthesis of $\mathrm{CuO}-\mathrm{TiO}_{2}$ catalyst with high dispersion $\mathrm{CuO}$ species for selective catalytic oxidation of NO. Appl Surf Sci 411:227-234. https://doi.org/10.1016/j.apsusc.2017.03.107

24. Guo RT, Hao JK, Pan WG, Yu YL (2015) Liquid phase oxidation and absorption of NO from flue gas: a review. Sep Sci Technol 50(2):310-321. https://doi.org/10.1080/01496395.2014.956761

25. Khan NE, Adewuyi YG (2010) Absorption and oxidation of nitric oxide (NO) by aqueous solutions of sodium persulfate in a bubble column reactor. Ind Eng Chem Res 49(18):8749-8760. https://doi. org/10.1021/ie100607u 
26. Fang P, Cen C, Wang X, Tang Z, Tang Z, Chen D (2013) Simultaneous removal of $\mathrm{SO}_{2}$, NO and $\mathrm{Hg}^{0}$ by wet scrubbing using urea $+\mathrm{KMnO}_{4}$ solution. Fuel Process Technol 106:645-653. https ://doi.org/10.1016/j.fuproc.2012.09.060

27. Mondal MK, Chelluboyana VR (2013) New experimental results of combined $\mathrm{SO}_{2}$ and $\mathrm{NO}$ removal from simulated gas stream by $\mathrm{NaClO}$ as low-cost absorbent. Chem Eng J 217:48-53. https://doi. org/10.1016/j.cej.2012.12.002

28. Collins MM, Cooper CD, Dietz JD, Clausen CA III, Tazi LM (2001) Pilot-scale evaluation of $\mathrm{H}_{2} \mathrm{O}_{2}$ injection to control $\mathrm{NO}_{x}$ emissions. J Environ Eng 127(4):329-336. https://doi. org/10.1061/(ASCE)0733-9372(2001)127:4(329)

29. Zhang WX, Jiang F (2019) Membrane fouling in aerobic granular sludge (AGS)-membrane bioreactor (MBR): effect of AGS size. Water Res 157:445-453. https://doi.org/10.1016/j.watre s.2018.07.069

30. Chen WS, Mo JH, Du X, Zhang ZE, Zhang WX (2019) Biomimetic dynamic membrane for aquatic dye removal. Water Res 151:243-251. https://doi.org/10.1016/j.watres.2018.11.078

31. Charbouillot T, Brigante M, Mailhot G, Maddigapu PR, Minero C, Vione D (2011) Performance and selectivity of the terephthalic acid probe for $\mathrm{OH}$ as a function of temperature, $\mathrm{pH}$ and composition of atmospherically relevant aqueous media. J Photochem Photobiol A 222(1):70-76. https://doi.org/10.1016/j.jphot ochem.2011.05.003

32. Liu Y, Adewuyi YG (2016) A review on removal of elemental mercury from flue gas using advanced oxidation process: chemistry and process. Chem Eng Res Des 112:199-250. https://doi. org/10.1016/j.cherd.2016.06.024

33. Sottmann J, Nataf L, Chaix L, Pralong V, Martin C (2018) Playing with the redox potentials in ludwigite oxyborates: $\mathrm{Fe}_{3} \mathrm{BO}_{5}$ and $\mathrm{Cu}_{2} \mathrm{MBO}_{5}(\mathrm{M}=\mathrm{Fe}, \mathrm{Mn}$, and $\mathrm{Cr})$. J Phys Chem C 122(30):1704217048. https://doi.org/10.1021/acs.jpcc.8b03734

34. Han Z, Yang S, Pan X, Zhao D, Yu J, Zhou Y, Xia P, Zheng D, Song Y, Yan Z (2017) New experimental results of NO removal from simulated flue gas by wet scrubbing using $\mathrm{NaClO}$ solution. Energy Fuels 31(3):3047-3054. https://doi.org/10.1021/acs.energ yfuels.6b03062

Publisher's Note Springer Nature remains neutral with regard to jurisdictional claims in published maps and institutional affiliations.

\section{Affiliations}

\section{Hongrui Sun ${ }^{1} \cdot$ Guanghui Yang $^{1} \cdot$ Tallal Bin Aftab $^{1} \cdot$ Fei Xue $^{1} \cdot$ Zhengguo Xiao $^{1} \cdot$ Qihao Guo $^{1} \cdot$ Dengxin Li $^{1}$}

\author{
Hongrui Sun \\ hongrui_93@163.com \\ Guanghui Yang \\ guanghuiyangygh@163.com \\ Tallal Bin Aftab \\ tallal@live.com \\ Fei Xue \\ xuefeiwin@outlook.com
}

\author{
Zhengguo Xiao \\ 516338462@qq.com \\ Qihao Guo \\ guoqihao@mail.dhu.edu.cn \\ 1 School of Environmental Science and Engineering, Donghua \\ University, 2999 North Renmin Road, Shanghai 201620, \\ China
}

